\title{
Implementing a social norms approach to reduce alcohol abuse on campus: Lessons learned in the shadow of 'The World's Largest Six-Pack'
}

\author{
Douglas J. Swanson , Kristine M. Zegers, Aaron A. Zwaska \\ Department of Communication Studies, University of Wisconsin-La Crosse, 1725 State Street, La Crosse, WI \\ 54601, USA
}

\begin{abstract}
Many institutions of higher education are struggling with the problem of excessive alcohol consumption by students. Colleges and universities want to be 'good neighbors' in their communities and must limit legal and social risks that result from excessive alcohol consumption by students. At the same time, colleges and universities operate in an increasingly challenging marketplace where many prospective students seek out institutions with a 'party school' reputation. Thus, higher education institutions are finding it difficult to define and carry out alcohol reduction measures that satisfy all constituents. This article discusses the approach taken at the University of Wisconsin-La Crosse. UW-L is an institution that identified a serious alcohol consumption problem and had to address the problem in a community where high levels of alcohol consumption are socially and culturally condoned. The article profiles the UW-L community and discusses the campaign model and strategy chosen. Quantitative and qualitative measures of success are discussed, along with lingering issues of resistance. The article ends with a summary of current issues and future directions being taken by the campaign.
\end{abstract}

\section{Introduction}

Numerous negative consequences result from excessive alcohol consumption by college students. Aside from the fact that alcohol abuse is a major public health problem (Wechsler \& Kuo, 2000), alcohol abuse by college students has been strongly correlated with poor academic performance and high student attrition rates (Elston, 1991). Because the college student's peer group is "the single most potent source of influence" during the undergraduate years (Astin, 
1997, p. 398), alcohol abuse can easily bring about socially inappropriate and sometimes criminal behavior (DeJong et al., 1998). Because there are first-hand and second-hand impacts of excessive alcohol consumption on the college campus (Wechsler, Lee, Kuo, \& Lee, 2000) it is clear that the quality of every student's educational experience is lessened when alcohol problems are allowed to exist.

The alcohol abuse problem in U.S. higher education began receiving significant research attention in the mid-1980s. Since that time, a number of theoretical models have been developed to give perspective on the issue. As a result of these models, college students have been targeted with a variety of prevention strategies. Most strategies target binge drinking, the consecutive consumption of alcoholic beverages-five in a row for men; four in a row for women (Wechsler, Davenport, Dowdall, Moeykens, \& Castillo, 1994).

Despite extensive effort, however, the abuse of alcohol is still a widely-publicized campus problem nationwide (Kluger, 2001). Students still perceive heavy drinking as a "rite of passage" (Irvine, 2001). A report to college and university presidents published in 1997 estimated that 1.3 million American college students were frequent binge drinkers (Be vocal. Be visible. $\mathrm{Be}$ visionary, 1997). On most campuses, most of the time, extensive alcohol consumption remains the norm rather than the exception (DeJong et al., 1998; Study blasts culture, 2002; Wechsler, Kelly, et al., 2000).

Most observers seem to agree that a widespread resolution of the problem will not take place without a fundamental change in thinking that would lead students to begin "rejecting the foolish, self-destructive use of alcohol" (Dampening student drinking, 1998, p. 8). Perhaps nowhere in the country has this change in thinking been attempted in a more challenging environment than at the University of Wisconsin-La Crosse (UW-L).

UW-L is a highly respected suburban comprehensive university of approximately 8,500 students with a well-ingrained 'jock school' image. It is located in a state that has among the nation's highest levels of per-capita alcohol consumption and reported incidents of binge drinking, and in a community with the state's largest number of licensed taverns per capita. The city's largest public event each year is Oktoberfest, a beer-centered celebration that has been identified by national news media as among the world's top ten most extensive festivals of its type. As a community, La Crosse's protectionist attitude about alcoholic beverage consumption is probably best symbolized by 'The World's Largest Six Pack,' a 388,000-gallon brewery storage facility that is promoted world-wide as a tourist attraction.

Despite these and other social, cultural, and environmental challenges, the university's campaign to change perceptions about alcohol use has been remarkably successful. While it is certainly true that campaign strategies are unique to the institutions and communities in which they are applied (see Keeling, 2000) there is much that can be learned from studying what has taken place at UW-L.

The following report discusses theoretical models and strategies for dealing with alcohol abuse, and the choices made by UW-L to reach campus and community groups that had widely divergent interests. Major qualitative and quantitative successes of the first three years of the UW-L campaign are presented. The report ends by summarizing directions that are planned for the campaign in the future. 


\subsection{Models and strategies}

Alcohol prevention strategies chosen for use on the college campus typically result from the selection of a theoretical model on which to base assumptions about the alcohol consumption experience. Because each model conceptualizes the problem and the environment in different ways, it is important for higher education administrators to select the model that seems most suited to their institution's particular alcohol-related issues.

A prohibition model seeks to establish an environment where students are prevented from accessing alcoholic beverages. A model of this type is often used at Christian colleges and universities, where students' behaviors are expected to conform to a doctrinal standard. Prevention strategy centers around the establishment of a strong institutional authority to prevent student access to alcohol.

The 'enforcement' model, sometimes referred to as the 'zero tolerance' model, works in a similar fashion. Though alcohol may not be removed from the environment, the institution establishes authoritative policies regulating alcohol consumption. Prevention strategy centers on institutional punishment of policy violators, a strategy that some experts contend relies on the operationalizing of "scare tactics" (Haines, 1997, p. 1). The University of Delaware has received notoriety for its enforcement model policy (Center for Alcohol and Drug Studies, 2002). UD expels students from campus after three alcohol use violations (Callaway, 1999). Supporters claim that a no-tolerance environment is particularly appealing to parents of incoming college freshmen. On the other hand, opponents believe an enforcement model "violates the civil liberties of legal adults" while promoting ignorance about the impact of alcohol in a community (Realistic alcohol laws, 2002).

The disease model recognizes the 1966 American Medical Association declaration that identified alcoholism as a disease. Prevention strategy focuses on directing institutional resources toward intervention and treatment. Closely related to this model is the development model, which presumes that alcohol problems develop as a result of shortcomings in the personal developmental process. Prevention strategy focuses on life skill development, particularly among those who have not yet reached adulthood (Higher Education Center, 2001).

The social norms model assumes that decisions about alcohol use are often made as a result of mis-perception of the norms for behavior in a social environment. Simply put, college students make "inflated estimates" of the level of alcohol consumption (Kluger, 2001, p. 44) and then behave accordingly. Prevention strategy is non-adversarial and focuses on using the media to show students that their peers are "not as reckless as they think" (Kluger, 2001, p. 42). Positive, inclusive, empowering messages illustrate actual norms and refute popular mis-perceived norms (Johannessen, Collins, Mills-Novoa, \& Glider, 1999).

The environmental management model assumes "people's behavior is shaped by their environment, so if we are to change their behavior, we need to change that environment" (DeJong et al., 1998, p. 5). Prevention strategy for the environmental management model is mostly non-adversarial, involving four elements: Strict enforcement of alcohol consumption laws and campus behavior codes, intervention to encourage moderation in alcohol consumption, an educational effort in regard to the impact of alcohol on the community, and establishment of alcohol free or 'alternative' activities for students (Higher Education Center, 2001). Strategies are 
developed cooperatively between the institution and community whenever possible (Gebhardt, Kaphingst, \& DeJong, 2000).

UW-L administrators examined all of these models as they began a series of meetings in 1998 to develop ways of dealing with the alcohol abuse problem and its consequences on campus and in the local community. The selection of an appropriate model or models was a critical decision to be made in light of the numerous social, cultural, and environmental challenges present at the state, city, and campus levels.

\subsection{The community}

From the outset, UW-L campaign planners' efforts to change the way alcohol is thought about and used by students faced tremendous resistance to change. To understand this resistance, one must go no further than to examine the way alcohol itself is conceptualized-and the way its use is socialized-in Wisconsin.

In 1998, alcohol consumption in Wisconsin was estimated at 2.69 gallons per person, a figure that ranks the state $20 \%$ above the average of all states (per capita alcohol consumption databases, 2002). In the year 2000 , more than $71 \%$ of Wisconsin adults reported drinking alcohol and one in four reported a history of binge drinking. During a campus forum addressing alcohol-related issues, the chair of the UW-L psychology department noted the "generational support for large levels of drinking" in the state (Morgan, 2002, personal communication). There was agreement among forum participants that, in Wisconsin, a high level of alcohol consumption does not have the negative social implications that it would elsewhere.

La Crosse, Wisconsin, with a population of 51,000, is the 228th largest metropolitan area in the U.S. and the 12th largest community in Wisconsin. Alcohol is available in dozens of La Crosse restaurants, sports venues, and at least one laundromat. The city is home to 134 licensed taverns.

In the early fall, the city heavily promotes its Oktoberfest, a celebration that begins with the public opening of a golden beer keg. Oktoberfest is 10 days of city-sanctioned revelry that triples the city's population with parties, parades, concerts, and numerous gatherings where public alcohol consumption is expected and even encouraged. Over the years, many UW-L faculty and staff members, campus organizations and student groups have played an active role in Oktoberfest.

UW-L, with approximately 8,500 students enrolled in 80 undergraduate and 21 graduate programs, is the third largest of the 13 four-year higher education institutions within the Wisconsin System. The vast majority of UW-L students are under 23 years of age. About $30 \%$ live in on-campus housing, most of which is co-educational. Another $40 \%$ of students live within a few blocks of campus. Beer is sold in the student union and the campus is within walking distance of the downtown district where many of the city's largest taverns attract students with 'all you can drink' specials for as little as $\$ 4$ per person. In 2000, $81 \%$ of UW-L students surveyed reported drinking alcohol; $75.3 \%$ reported at least occasional binge drinking. More than half (50.4\%) reported drinking six or more alcoholic drinks during the last occasion they "partied" (Vanvoorhis \& Sullivan, 2000).

More than $28 \%$ of UW-L students major in a field related to athletics, and the school is wellrespected nationally for its Physical Education, Fitness, Sport Management, and Community 
Health Education programs. University athletic teams have earned numerous athletic conference championships as well as 39 national titles in nine sports. Intramural and club sports are among the most popular activities on campus. As a result, UW-L as an institution has an unshakable 'jock school' reputation. This, too, suggests heavy alcohol consumption among students-since previous research has found that heavy drinking among college athletes is the norm rather than the exception (Thombs, 2000).

When one considers Wisconsin's cultural norms for alcohol consumption, La Crosse's easygoing nature about the business of alcohol promotion and sales, and UW-L's image as a regional 'jock school,' it is easy to see UW-L could be perceived as a place where the pursuit of fun is more intensive than the pursuit of learning. Higher education institutions in such a situation find it difficult to change public perceptions (see Sperber, 2000).

\subsection{Campaign organization and strategy}

The UW-L Campus Alcohol Task Force (CATF) was appointed by the university chancellor in May, 1998 as an administrative response to three troublesome situations: (1) An increase in the number of alcohol-related fatal accidents in 1997 on college campuses across the nation; (2) increasing student protests and demonstrations related to students' 'right to party'; and, (3) increasing pressure from state legislators as well as members of campus governance groups that Wisconsin higher education institutions should promote activities that change cultural expectations of alcohol consumption on college campuses.

The 21-member committee included administrators from a variety of campus units that most impact students-residence life, student activities, protective services, and the campus counseling and testing office. Several faculty members and five students were included on the panel. CATF members spent more than a year developing a campus community profile, defining specific problems, collecting data, identifying possible responses, and discussing implementation strategies (Alcohol Task Force, 1999). Student participation was encouraged in every step of the process-but particularly in two public forums. Tim Brooks, University of Delaware dean of students, was brought to UW-L to make a presentation and answer questions about the UD policy. Michael Haines, director of the National Social Norms Resource Center at Northern Illinois University, was brought to campus in a separate visit to make a presentation on the social norms model used at NIU.

Encouraged by student feedback from the public forums, CATF members determined that the social norms approach was the most appropriate response to the alcohol problems at UW-L (Alcohol Task Force, 1999). The committee voted to adopt the social norms and environmental management models under which a "prevention/moderation approach" would be taken (Social norms marketing, 2001). The task of carrying out the campaign was given to UW-L Reach \& Share, a peer education program that had been active for several years on campus and had experience dealing with the wide variety of social and health issues faced by college students. UW-L Student Activities and UW-L Residence Life came up with funding to hire a professional staff coordinator and in June, 2000, the UW-L campaign was formally introduced. 


\subsection{Campaign tactics and media}

In its first two years, the UW-L campaign relied heavily on the use of on-campus media to support the main theme that Most UW-L students have 0-5 drinks per week. The quantitative measure in the theme referred to the statistically established average level of alcohol consumption by more than $50 \%$ of UW-L undergraduates. The overall message of the theme represented an effort to illustrate the positive-that excessive alcohol consumption is not necessary for students to have a fulfilling social experience at UW-L.

The theme was publicized via a variety of promotional advertisements sufficiently disseminated across campus so that students were repeatedly exposed to the theme and supporting concepts. Reach \& Share staff designed all messages in-house with the help of the program manager, social marketing program coordinator, student program assistants, a graphic artist, student presentation leaders and volunteers.

Most promotional advertisements took the form of four-color posters that featured a single prominent photo of UW-L students engaged in attractive, pro-social behaviors. Typically, one or more brief text messages accompanied each photo to narratively affirm the idea that students could socialize and have fun without the use of alcohol (see Fig. 1). Each advertisement included the UW-L institutional logo, Reach \& Share logo, the 0-5 campaign logo, and source reference for any statistical claims made. In the 2000-2001 academic year, the campaign produced and disseminated on campus 1,500 posters and 1,800 flyers featuring four different scenes and messages related to the campaign theme.

During that same period of time, 200 'table tent' promotional advertisements were created and placed on dining room tables in the student center. Because these items had a limited life span, they were usually implemented to promote Reach \& Share-sanctioned activities tied to the campaign. The campaign also placed weekly advertisements in the student newspaper, and placed advertisements in the annual UW-L student directory, student planner, and campus guidebook.

All elements-including copy, design, graphic elements and photography-were extensively focus group tested by Reach \& Share before any advertisements were placed. All advertisements were subjected to extensive evaluation to assure that the advertisements worked in harmony with each other while supporting the $0-5$ theme and related concepts.

Campaign planners tried to make use of 'free media' publicity whenever possible. A good working relationship was established with the editors of the campus faculty/staff newsletter, and articles were regularly produced for that publication. Reach \& Share student staff members regularly engaged in a discussion of alcohol-related issues on the editorial pages of the student newspaper, as well. In the 2000-2001 academic year, two articles about the campaign were published in the faculty/staff newsletter. Two editorials and six letters to the editor were published in the student newspaper; all were supportive.

\subsubsection{Promotional items}

The campaign made extensive use of promotional items to support the campaign. These items included ballpoint pens, water bottles, stadium cups, refrigerator magnets and bookstore give-away items imprinted with the $0-5$ theme. The items were distributed to students at freshman registration, at athletics team organizational meetings, at residence hall meetings, 


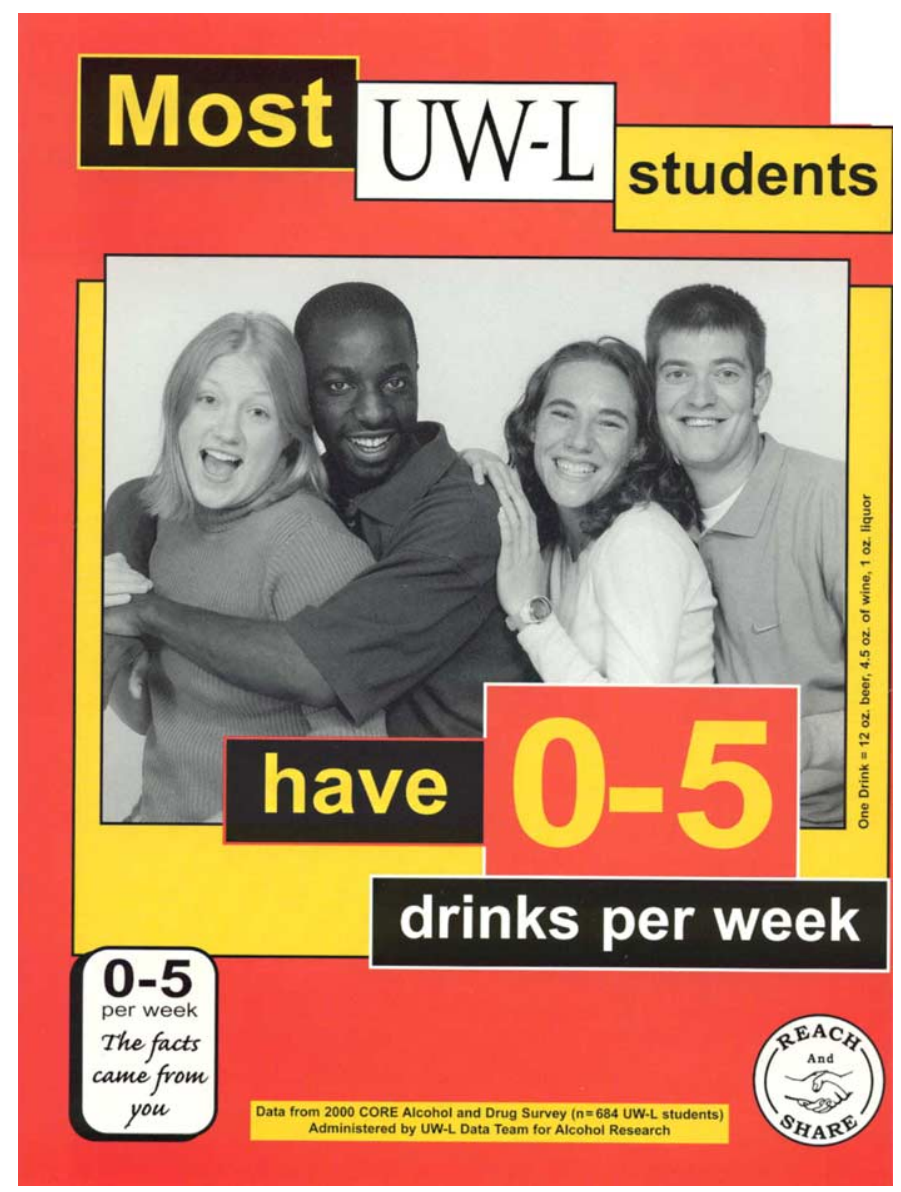

Fig. 1.

and in the campus bookstore at the beginning of each semester. Items were also distributed at other events throughout the academic year.

The $0-5$ theme was imprinted on computer mouse pads placed in one of the campus computer labs. The theme on the mouse pads was supplemented by a scrolling 'screen saver' message installed on the computers themselves.

In the 2000-2001 academic year, the campaign produced and disseminated more than 1,000 pens, 500 water bottles, 400 stadium cups, and 1,400 magnets. The campus bookstore gave away 6,000 plastic bags, 1,500 bookmarks and 5,000 student ID card holders imprinted with the campaign theme.

\subsubsection{Student presentations}

Because students and others in the campus community "may not entirely understand the point of the campaign until they have had all their questions answered and doubts addressed" (Social norms marketing, 2001, p. 3) the UW-L campaign put a strong emphasis on presenting the $0-5$ theme in group meetings - particularly those involving students. 
Reach \& Share student presenters began the school year with meetings during freshman orientation sessions. Presentations continued throughout the regular school year in classes, activity groups, faculty/staff groups, and in residence hall assemblies. While presenters opened each discussion and led students and others in a talk about the issues, participants were encouraged to express their opinions about alcohol and its impact on their lives-both positive and negative. No discussion ended until everyone's opinion was heard. Although the focus of the campaign was primarily on campus, presentations also were given to local community and service groups in the La Crosse area so that as many community members as possible could be offered a voice in the process.

From the launch of the campaign in June, 2000, through the end of the 2000-2001 academic year, 88 presentations had been given to a total audience in excess of 5,700 students, faculty, staff, and community members.

\subsubsection{Curriculum infusion}

From its outset, the UW-L campaign was concerned with curriculum infusion, "a way for faculty to help educate students about the risks associated with high risk drinking choices by incorporating information and issues related to alcohol use into their class" (Alcohol and related issues, 2001). Curriculum infusion increases students' knowledge of alcohol-related issues and helps students make more informed choices. At the same time, because students are actively involved in learning about issues that directly affect their lives, they are better prepared to bring about positive change on campus. Faculty members using curriculum infusion reinforce the need for positive change.

A Curriculum Infusion Committee, a subcommittee of the CATF, was established for "providing faculty with information and techniques to help infuse alcohol prevention messages into classes" (Social norms marketing, 2001, p. 10). Most of the effort was focused on bringing a discussion of alcohol-related issues into the general education program, a common set of liberal studies and skills courses for all UW-L undergraduates that "engages students actively in learning and thinking about essential knowledge" (Undergraduate Catalog, 1999, p. 49).

While it is difficult to quantify participation by individual faculty, it is known that infusion took place in freshman and sophomore-level courses in communication, English, health, laboratory sciences, physical education, and psychology. Reach \& Share presenters were invited by faculty to lead discussions in 18 classes with 537 students during the 2000-2001 academic year.

\subsubsection{Focus groups}

Formal and informal focus group meetings were conducted throughout the course of the academic year. These meetings served several purposes. Initially, the meetings allowed more people in the campus community to be exposed to the theme of the campaign-and to have the intent of the campaign explained in its full significance. Perhaps most significantly, though, the administration of focus groups allowed campaign planners to gather qualitative and quantitative data to further strengthen the campaign.

During the 2000-2001 academic year, approximately two-dozen focus groups were held with students representing a variety of different demographic groups and with differing social, cultural and racial background. Reach $\&$ Share staff spend an extensive amount of time 
recording, transcribing, and then analyzing comments made in focus group meetings - to allow the campaign to get the most benefit possible from feedback by those most impacted by $0-5$.

\subsection{Indicators of change}

\subsubsection{Quantitative measures}

The primary quantitative indicator of success comes about through analysis of the Core survey results (Alcohol Task Force, 1999; Vanvoorhis, Elfessi, Ringgenberg, Ziemelis, \& Corcoran, 2001; Vanvoorhis \& Sullivan, 2000). The survey is an instrument created by the Core Institute, a non-profit organization that assists higher education institutions with drug and alcohol prevention efforts. The Core Alcohol and Drug Survey questionnaire is used by higher education institutions all over the U.S. as a pretest and posttest measure of the effectiveness of prevention efforts (Core Alcohol and Drug Survey, 2002). In 1999, a total of 582 UW-L undergraduates completed the instrument - allowing for the establishment of baseline data. In 2000, a total of 684 UW-L undergraduates completed the Core instrument. In 2001, a total of 1,014 UW-L undergraduates completed the instrument. All survey samples were obtained through a modified stratified random sampling of classes.

Results from the 1999 survey indicated that $88.4 \%$ of students reported a recent incident of personal alcohol consumption. Students reported an average rate of consumption of 8.3 drinks per week. More than half of all respondents indicated that past alcohol use led to personal involvement in public misconduct such as DWI, vandalism, or fighting.

Results from the 2000 and 2001 surveys showed that a continuing high level of alcohol use at UW-L. In both surveys, more than $80 \%$ of students reported a recent incident of personal alcohol consumption. But some signs of moderation began to appear. Half of the undergraduates reported drinking five or fewer alcoholic drinks per week and almost $70 \%$ of students reported drinking once per week or less. These signs of moderation in consumption are seen as a key quantitative measure of success for the campaign.

Some significant differences were observed between the 2000 and 2001 survey findings. Students' perceptions of alcohol consumption by their peers dropped from $65 \%$ of students overestimating their peers' level of consumption in 2000 to $50 \%$ overestimating in 2001. This more accurate perception of the UW-L campus norm is seen as a key quantitative measure of success for the campaign.

The most recent survey results suggest equally strong improvement in the extent to which students engage in protective behaviors. The percentage of students reporting that they choose not to drink, drink non-alcoholic beverages while 'partying', 'party' with people they know, watch out for friends who drink too much, pace their drinking, and use a designated driver all increased in 2001, as compared to the Core survey data from the previous year. These multiple indicators of increasing protective behavior are believed to be the result of an increasing dialogue on campus about alcohol-related effects and the direct consequence of these effects on students.

Other positive indicators of change have been quantified, as well. Among the most striking of these is a reduction in reports of the types of criminal activity often associated with high levels of drinking. La Crosse police calls for reports of vandalism and/or damage to property dropped by $50 \%$ city-wide and by $75 \%$ in the area immediately around the UW-L campus 
between October, 2000 and October, 2001 (Kent, 2001). This, too, is seen as an indicator of success in that students may be more aware of their actions and how actions impact the community.

\subsubsection{Qualitative measures}

During the first few months of the campaign, it was obvious that it would take time to expose all UW-L students to the $0-5$ theme. Among those students who were exposed to the theme or to related messages, few students accepted the concept. When interacting with Reach \& Share presenters, the vast majority of students reported strong disbelief that UW-L students would drink in moderation, or not drink at all—even through survey data confirmed these facts (Vanvoorhis \& Sullivan, 2000; Alcohol Task Force, 1999). During Reach \& Share presentations, students who expressed acceptance of the $0-5$ theme or messages often were ridiculed by their peers. As the Spring, 2001 semester began, campaign organizers began to witness dramatic changes. Nearly all students reported exposure to the $0-5$ theme. When asked about the theme or its related messages, larger numbers of students expressed acceptance.

During that semester, a striking event that took place that was seen initially as a campaign setback. In retrospect, however, it has been viewed as a positive measure of acceptance of the campaign theme and message. An unknown person or persons created and released on the Internet a series of parody posters making fun of the UW-L 0-5 theme and messages. Parody is an artistic work that mimics the original author's characteristic style by creatively making fun of the original work or pushing the stylistic boundaries of the original to extreme lengths (Zinkhan \& Johnson, 1994). The purpose of parody is to "achieve the degradation of something exalted ... by destroying the unity that exists between people's characters as we know them and their speeches and actions, by replacing either the exalted figures or their utterances by inferior ones" (Freud, 1960, p. 257). This was certainly the case on the UW-L campus. Over the period of a few months, more than a half-dozen posters were circulated. Word of the existence of the parodies spread like wildfire by e-mail (see Fig. 2).

The posters were linked online to a parody website modeled after the UW-L home page. The posters and the website made fun of $0-5$ themes, in most cases using sexual innuendo and sexually explicit photographs. The initial reaction of Reach \& Share was one of panic. But since no real harm was done-other than copyright and trademark violation — the staff quickly realized the parodies served only to increase the extent to which students were talking about the campaign. While Reach \& Share did not make any effort to call attention to the parodies, the staff did come to the understanding that parody only 'works' as a humorous form when those viewing the parody cognitively embrace the original (see Berger, 1993). Therefore, these initially disturbing posters and website came to be seen as just another indicator of success for the UW-L campaign.

By Fall, 2001, the campaign had achieved universal exposure among UW-L students to the $0-5$ theme and related messages. Students reported numerous individual exposures and expressed detailed understanding of different concepts related to the theme. The number of students expressing disbelief dropped dramatically. Incidents of peer ridicule were rare. Most importantly, even students who expressed disbelief in the $0-5$ theme still overwhelmingly perceived the campaign as a positive campus influence that should continue. The simple quantitative reference of $0-5$ was recognized universally as a concept related to "what students at 


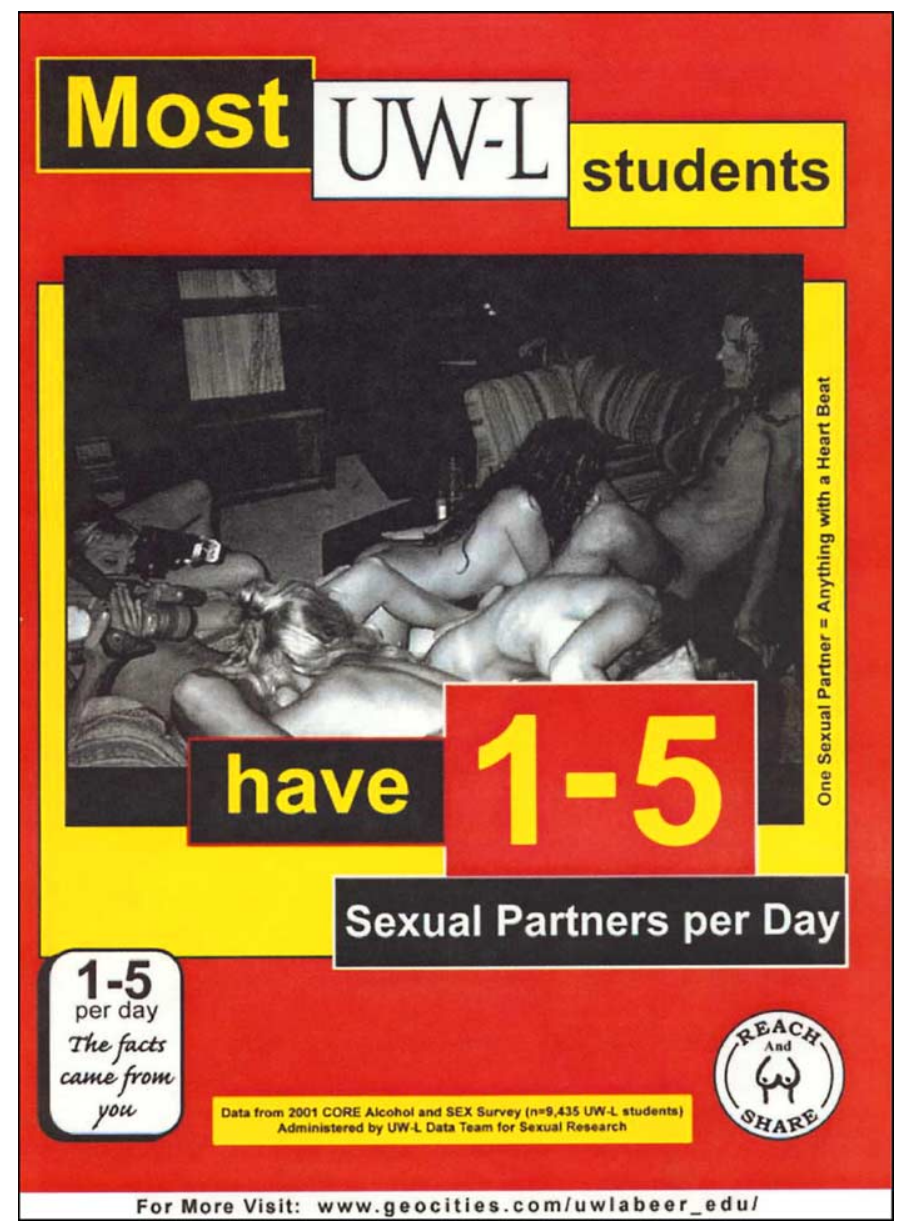

Fig. 2.

UW-L do.' Because students seemed so able to identify with $0-5$, the reference was used as an attention-getting humorous symbolic device that showed up promotionally in a variety of venues unrelated to the Reach \& Share campaign.

\subsection{Indicators of resistance}

Much of the resistance to the campaign theme and messages that was evidenced was expressed as mistrust of the Core survey data collection and statistical analysis methods. Some students had difficulty accepting that a survey sample of 684 (Vanvoorhis \& Sullivan, 2000) or even 1,014 of their peers (Vanvoorhis et al., 2001) would be sufficient to allow statistical estimations for a campus population of approximately 8,500. It was common for students to express the opinion that the campaign could not make claims about behavior "unless you survey everyone."

Ignorance of data collection and statistical methods was not exclusive to students. Faculty members complained the survey was "meaningless" because it "would not follow correct 
procedures." This claim was made despite the fact that the Core survey has been administered the same way for many years in higher education institutions all over the U.S.- and that, in the year 2000, more than 55,000 undergraduates in 132 institutions were surveyed. UW-L students repeatedly told of faculty who "bashed the campaign" and the survey in class discussions (see Social norms marketing, 2001, p. 8). Frequently, these faculty were known to have relaxed attitudes toward student drinking and perceived the campaign as repressive demagoguery, or had more conservative attitudes toward drinking, believed the campus was too permissive and needed a prohibition/punishment model campaign supported by strong fear appeals.

Faculty members whose expertise was outside of the humanities were not the only ones to fail to grasp the social norms concept. Even faculty who should most understand the idea expressed ignorance of the concept and its application. A tenured senior faculty member in communication questioned the existence of the campaign itself: "If the norm is the norm," he argued, "why do you need to promote it?" Another communications scholar-an expert on metaphor and social construct—ended a visiting lecture by asking why the campaign did not "use pictures of students vomiting, to discourage drinking."

Further resistance came by way of the community 'double standard' in regard to alcohol issues. During 1999-2000, a series of critical stories on local TV and in the La Crosse newspaper scolded students for alcohol-related property damage along streets near campus. These same media made no mention of the negative impact of Oktoberfest, when downtown streets were ankle-deep in trash and police on horseback were called in for crowd control. Reach \& Share focus group participants consistently identified these and other "contradictory messages" when locals expressed outrage at student alcohol consumption but supported community drinking celebrations (Social norms marketing, 2001, p. 7).

A lack of activities for UW-L students-particularly on holidays and weekends-continued to be troublesome. Although the university has made much progress in this area, a lack of available funds is a hindrance-especially since activities would be conducted during late night and weekend hours and additional staff would be required at those times. Reach \& Share staff continued to struggle with the semantics, since students shun any activity labeled as an "alternative."

Another area of concern throughout the initial phase of the campaign was the content and context of photographs used on the campaign posters. The earliest set of posters featured posed photos of students taken in a studio. In early focus group testing, these photos were widely criticized for being "cheesy" with an artificial appearance. The next set of posters featured photos of students taken on campus, outdoors, during the daytime. These photos were also criticized by students who associate daytime, on-campus photos with classes and studying — not socialization. It became apparent that students wanted to see photographs of their peers in what they perceived to be more realistic socialization settings-after dark, away from campus, in a context students associate with 'partying.' It remains a challenge for campaign planners to come up with ideas for photos that are consistent with the campaign theme but still reflect the type of socialization students most identify with.

Students also have criticized the poster photos for a lack of racial and cultural diversity. Minority group members constitute less than 5\% of the student population at UW-L; minority group representation in poster photos is much higher than 5\%. Still, focus group participants tend to see the posters as more 'white' and less 'diverse' than the UW-L campus at large. 
Campaign planners have struggled with the issue of how to involve more students of color in the poster photos, in a naturally appearing way. A related issue is the involvement of gay, lesbian, bisexual and transgendered students. Campaign planners do not want to exclude GLBT students; they also do not want to include students in a way that appears artificial or condescending. In recent months, Reach \& Share staff began a small, grant-funded research effort specifically targeted toward GLBT student groups on campus- to find out what they think about the campaign and how they would like to be involved in it.

\subsection{Future directions}

As the 2001-2002 academic year began, it became clear that the campaign was needing to advance the alcohol awareness strategy in different directions. It was felt that the saturation point had been reached with the 0-5 theme. Students universally understood what the theme was and what it meant. Qualitative data from focus group interviews validated what Haines refers to as "the habituation phenomenon" (Haines, 2002). Students exposed to the same kinds of messages in the same ways get accustomed to the symbolism and tend to "tune out" future communication that employs the same symbolism.

Reach \& Share received a \$5,000 UW-L Inter-Unit Collaboration Grant to research future directions for the campaign. In particular, the grant proposed to "expand our social norms campaign with specific message strategies and outcome goals that address UW-L's underrepresented populations - multicultural, GLBT, international students, and students with disabilities" (Inter-Unit Collaboration Grant, 2002, p. 1). The grant funds paid for a two-day consultation visit early in the Spring, 2002 semester, by Michael Haines and two of his associates from the National Social Norms Resource Center.

As a result of that visit - and in coordination with the goals of the Inter-Unit Collaboration Grant — the campaign was taking a number of actions in late Spring, 2002:

- A research assistant was hired and trained, and was conducting focus groups with multicultural and GLBT participants. Information obtained from these focus groups will help plan future campaign strategy as well as help guide the creation of specific design and message elements.

- A campus website addressing alcohol and other drug issues was designed, was approved, and was under construction. The website will be linked to a new UW-L institutional site, which was also in the development phase for launch in the 2002-2003 academic year.

- The campaign was making additional outreach efforts to local retailers, informing them about the campaign and encouraging them to help prevent underage drinkers from consuming alcohol. Campaign planners also were engaged in a dialogue with retailers about 'all you can drink' specials and other retailer strategies that encourage excessive consumption.

- The campaign was shifting its message strategy away from the quantitative measure of $0-5$ and toward the more positive and inclusive concept of "protective, proactive behaviors" (Haines, 2002). Protective behaviors include the establishment of activities not associated with alcohol, the use of a designated driver, the concept of 'partying with friends,' being aware of personal consumption rates, and so forth. 


\section{Conclusion}

As the UW-L campaign prepared to enter its third academic year, it was clear the effort had succeeded despite a number of social and environmental challenges in the community. Numerous quantitative and qualitative measures of success had been noted. The campaign's $0-5$ theme has become part of the symbolism of the university - and there has been universal campus exposure to the media messages that explain and develop the theme. There had been a significant drop in the extent to which UW-L students over-perceive the amount of drinking by their peers. There had been no change in the total number of students who report alcohol consumption-at least $85 \%$ drink, and many of those who do are underage drinkers. But there had been an increasing dialog about alcohol use, and that dialogue is accelerating. Students, administrators, faculty, and staff are more aware of alcohol consumption - and that awareness is being shared with the community at large. On the UW-L campus, the campaign is making a stronger effort to reach out to under-represented groups and bring them into the discussion of alcohol use. As the campaign moved away from the quantitative $0-5$ theme and toward an emphasis on protective behaviors, it is hoped that there will be continued growth in the discussion of what's really important-how to keep students safe from harm, regardless of whether or not they choose to drink alcohol.

\section{References}

Alcohol and related issues. (2001). Richmond, VA: University of Richmond URWell Program. Retrieved February 6, 2002 from http://www.richmond.edu/student/affairs/infusion/whatisit.html.

Alcohol Task Force Final Report. (1999). La Crosse: University of Wisconsin.

Astin, A. W. (1997). What matters in college: Four critical years revisited. New York: Jossey-Bass.

Berger, A. A. (1993). An anatomy of humor. New Brunswick, NJ: Transaction Publishers.

Be vocal. Be visible. Be visionary. Recommendations for college and university presidents on alcohol and other drug prevention. (1997). Washington, DC: U.S. Department of Education, Higher Education Center for Alcohol and Other Drug Prevention.

Callaway, B. (1999, April 20). UD targets underage and overconsumption of alcohol on campus. The Review, p. 1.

Center for Alcohol and Drug Studies. (2002). A collaborative plan to reduce irresponsible drinking at UD. Newark, DE: University of Delaware. Retrieved February 1, 2002 from http://www.udel.edu/cdas/drinking.html.

Core Alcohol and Drug Survey. (2002). De Kalb, IL: National Social Norms Research Center. Retrieved January 7, 2002 from www.socialnorm.org/core.html.

Dampening student drinking. (1998, December 17). The Christian Science Monitor, p. 8.

DeJong, W., Vince-Whitman, C., Colthurst, T., Cretella, M., Gilbreath, M., Rosati, M., \& Zweig, K. (1998). Environmental management: A comprehensive strategy for reducing alcohol and other drug use on college campuses. Washington, DC: U.S. Department of Education, Higher Education Center for Alcohol and Other Drug Prevention.

Freud, S. (1960). Jokes and the comic. In J. Strachey (Ed.), Jokes and their relation to the unconscious (pp. 180-221). New York: W.W. Norton.

Gebhardt, T. L., Kaphingst, K., \& DeJong, W. (2000). A campus-community coalition to control alcohol-related problems off campus: An environmental management case study. Journal of American College Health, 48, 211-216.

Haines, M. (1997, Fall). Spare the rod and get results: A wellness approach to health promotion media. Wellness Management, 13(3), 1-4. 
Haines, M. (2002, February 8). Social norms presentation. University of Wisconsin-La Crosse.

Higher Education Center for Alcohol and Other Drug Prevention. (2001). Prevention models. Washington, DC:

U.S. Department of Education, Higher Education Center for Alcohol and Other Drug Prevention.

Inter-Unit Collaboration Grant. (2002). Reach \& Share. University of Wisconsin—La Crosse.

Irvine, M. (2001, June 1). Bush stirs talk on underage drinking. Retrieved June 8, 2001 from http://www.edc.org/hec/.

Johannessen, K., Collins, C., Mills-Novoa, B., \& Glider, P. (1999). A practical guide to alcohol abuse prevention: A campus case study in implementing social norms and environmental management approaches. Tucson, AZ: The University of Arizona.

Keeling, R. P. (2000). Social norms research in college health. Journal of American College Health, 49, 53-56.

Kent, J. (2001, November 4). Vandalism reports down. La Crosse Tribune, pp. A1-A7.

Kluger, J. (2001, June 18). How to manage teen drinking (the smart way). Time, pp. 42-44.

Per capita alcohol consumption databases. (2002). Bethesda, MD: National Institute on Alcohol Abuse and Alcoholism. Retrieved January 14, 2002 from www.niaaa.nih.gov/databases.

Realistic alcohol laws for legal youth. (2002). Retrieved January 24, 2002 from http://www.rallyusa.org/ education.html.

Social norms marketing campaign: Final report. (2001). La Crosse, WI: University of Wisconsin, La Crosse.

Sperber, M. (2000). Beer and circus: How big-time college sports is crippling undergraduate education. New York Henry Holt and Co.

Study blasts 'culture of drinking' at colleges. (2002, April 10). La Crosse (Wisc.). Tribune, p. 1.

Thombs, D. L. (2000). A test of the perceived norms model to explain drinking patterns among university student athletes. Journal of American College Health, 49, 75-84.

Undergraduate Catalog 1999-2001. (1999). La Crosse: University of Wisconsin.

Vanvoorhis, C. R. W., Elfessi, A., Ringgenberg, L., Ziemelis, A., \& Corcoran, M. (2001, July). Preliminary summary of UW-La Crosse alcohol task force data collection. Unpublished document, University of Wisconsin-La Crosse.

Vanvoorhis, C. R. W., \& Sullivan, S. M. (2000, April). Preliminary summary of UW-La Crosse alcohol task force data collection. Unpublished document, University of Wisconsin-La Crosse.

Wechsler, H., Davenport, A., Dowdall, G., Moeykens, B., \& Castillo, S. (1994). Health and behavioral consequences of binge drinking in college: A national survey of students at 140 campuses. Journal of the American Medical Association, 272, 1672-1677.

Wechsler, H., Kelly, K., Weitzman, E. R., San Giovanni, J. P., \& Seibring, M. (2000, March). What colleges are doing about student binge drinking. Journal of American College Health, 48, 219-227.

Wechsler, H., \& Kuo, M. (2000, September). College students define binge drinking and estimate its prevalence: Results of a national survey. Journal of American College Health, 49, 57-64.

Wechsler, H., Lee, J. E., Kuo, M., \& Lee, H. (2000). College binge drinking in the 1990s: A continuing problem. Journal of American College Health, 48, 219-227.

Zinkhan, G. M., \& Johnson, M. (1994). The use of parody in advertising. Journal of Advertising Research, 23, III-VIII. 